\title{
Erratum to: The Use of Structural-Parametric Approach for Approximation of Terrain Relief
}

\author{
I. E. Stepanova ${ }^{a, b}$ *, A. V. Shepetilov ${ }^{c}$, and V. V. Pogorelov ${ }^{a, b}$ \\ ${ }^{a}$ Schmidt Institute of Physics of the Earth, Russian Academy of Sciences, Moscow, 123242 Russia \\ ${ }^{b}$ Sirius University of Science and Technology, Sochi, 354340 Russia \\ ${ }^{c}$ Moscow State University, Department of Physics, Moscow, 119991 Russia \\ *e-mail: tet@ifz.ru \\ Received July 26, 2021; accepted July 26, 2021
}

DOI: $10.1134 / \mathrm{S} 106935132111001 \mathrm{X}$

Page 900, line 8 from top, the dates should read as follows:

Received January 20, 2020; revised July 7, 2020; accepted July 8, 2020

The original article can be found online at

https://doi.org/10.1134/S1069351320060105 